\title{
THE SO-CALLED “CYANIDE CASE" IN GEORGIAN MEDIA
}

\section{Mariam Adamashvili}

Doctor of Social Sciences, Assistant Professor, Georgian National University SEU

\begin{abstract}
Religion and related aspects are a very sensitive issue both in Georgia and in the world. Consequently, incorrect coverage of such issues may lead to the escalation of strong public controversy and conflicts. As the media is generally considered to be the best tool for shaping public opinion, the journalist must take into account ethical norms and relevant legislation in the process of covering these issues as well as be guided by internationally accepted standards of religious coverage.

Digesting religious topics and preparing a media product on related issues have become especially persistent in Georgia in recent years, as the number of religious crises and conflicts has increased significantly. In this regard, our paper is dedicated to exploring one of the crucial events in Georgia: the so-called "Cyanide Case". We will endeavor to reveal the angle from which the Georgian media covered the crisis.

As unimaginable as it may seem, it was the manner of the request for the accused clergyman to receive the rite of communion, including the making of this request by atheist celebrities at the rally, that triggered the discrimination against the church. It is noteworthy that after calling for providing Giorgi Mamaladze with the communion, the attack on the church continued with another request to make a demand to His Holiness and Beatitude Illia II of Georgia to mediate with the President to grant a pardon to the Dean in parallel with the deteriorating health of the clergyman. In due time, they were forced to at least acknowledge the power of the Patriarch's word. One could not easily forget one simple detail of Georgian law providing for the initiation of early release due to deteriorating health; though, the authors of this request needed to create the image of a persecuted person by the church through the arrested Dean.
\end{abstract}

Keywords: the "Cyanide Case"; the Patriarchal Throne; the Attack on the Church; the Patriarch in Germany.

\section{Introduction}

From time immemorial, from the day the universe was created, following the footsteps of the development of mankind, religion has been its accompanying event, which has its special significance and purpose in any civilization. Religion is a kind of philosophy of life that determines a particular action of humanity. Religion has existed at every stage of human development, continuously running through the history. The development of religion is closely related to the spiritual and intellectual development of man. While it may seem impossible for most of the earth's population to imagine themselves living without religion, many find it difficult to grasp the true meaning of religion.

Georgia has long existed at the crossroads of Eastern and Western religions: initially Mazdeism and later Islam. Thus, our country had to deal with mutually exclusive religions and cultures. Despite many difficulties, the Georgian nation had always aspired to Western culture. The Christian faith completely defined the way of 
development of the country and the nation. On the road laden with these difficulties, our nation never broke under pressure, and on the contrary, it kept aspiring more actively to the religious-cultural domain to which it has forever committed itself.

Georgia is a multinational and diverse country, both culturally and religiously. Caravan roads used to run through Georgia at one time, which naturally contributed to its cultural and religious diversity. Greco-Roman and Oriental polytheism tried to established itself next to the rituals or customs present here. People of different faiths have lived here peacefully next to each other for centuries, leaving their unique traces in the history of the country.

Orthodox Christianity has been the national religion of Georgians for 17 centuries. The struggle for Orthodoxy was also considered a struggle for the survival of the Georgian nation and sustaining its national interests. However, in our country, for centuries, people of other religions had historically had a chance of peaceful living. No one was persecuted on religious grounds. People of different faiths kept leaving a worthy mark for centuries on the nation's development path.

The general picture of the religious situation in Georgia is as follows: the majority of the Georgian nation is Orthodox; a significant part of their fellow citizens is Muslim, while, recently, quite a small number of believers have joined other religious organizations.

Orthodox Christianity has been an integral part of the Georgian nation for centuries and it can be said that for almost 17 centuries this religion has been our national faith. The protection of Orthodoxy, for our ancestors, also meant the protection of the Georgian language and culture, the territory of the country and the national identity from the enemies.

Thus, religion, which is represented by the Georgian Orthodox Autocephalous Church, has played an important role in the spiritual and cultural development of Georgia. On both historical and permanent basis, it has had a special place in the development of the country at all times and it can be said that the state formation of Georgia is hard to be imagined without considering the stance of the Georgian Orthodox Church and their relations.

Given the importance of the Georgian Orthodox Church, it is not surprising that the media often take great interest in the Orthodox Church, and religious issues are most often on their agenda during religious holidays. No single orthodox holiday or important sermon is left out of the media spotlight. For example, on Christmas or Easter, the Patriarch's epistle, the liturgy, the preparations for the holiday, the best wishes sent out by the representatives of the political elite are covered separately.

Weekly sermons of the Catholicos-Patriarch of All Georgia, Orthodox holidays, miraculous stories of certain church members, events planned by the Patriarchate make up the general picture of the coverage of religious topics in the Georgian media. Recently, however, religiously conflicting situations have also become of particular interest.

The sense of responsibility among journalists becomes especially important in the process of covering religious crises. While preparing a media product regarding a very sensitive topic of religion and related topics, the journalist should pay special attention to the facts in order to provide the audience with the most balanced and unbiased information. When covering religiously conflicting or sensitive situations, the journalist should offer a healthy media product to the public in order not to form stereotypes and/or misinterpret the facts, which may contribute to the escalation of the conflict between religious groups. Media representatives should be able to avoid an escalation of such a situation. 
Religion and related issues are a very sensitive issue both in Georgia and in the world. Therefore, incorrect coverage of these issues may contribute to the escalation of strong public and conflict. As the media is the best tool for shaping public opinion, the journalist must take into account ethical norms and relevant legislation in the process of covering these issues, as well as be guided by internationally accepted standards of religious coverage.

Digesting religious topics and preparing a media product on related issues have become especially persistent in Georgia in recent years, as the number of religious crises and conflicts has increased significantly. In this regard, our paper is dedicated to exploring one of the crucial events in Georgia: the so-called "Cyanide Case". We will endeavor to reveal the angle from which the Georgian media covered the crisis.

As part of our media monitoring, media outlets as well as the political sector and the clergy, were monitored. The daily news program and talk show of non-religious television were selected as the subject of monitoring. In particular, the monitoring was carried out on the following subjects:

- Public Broadcaster ("Moambe");

- Rustavi 2 ("Kurieri”, "PS");

- TV Imedi ("Kronika",);

- TV Pirveli (“Daily News", "Reaction”, "Nodar Meladze’s Saturday”).

Upon the media monitoring carried out within the framework of the research, it became possible to see a comprehensive picture of the "Cyanide Case" in the Georgian media. We hope that the existing material will facilitate discussions, which are mainly influenced by different interests and it will be possible to start a constructive dialogue between all stakeholders in terms of religion coverage, in order to improve the situation of the local journalism.

\section{The Review of the "Cyanide Case"}

Dean Giorgi Mamaladze is connected with one of the most obscure and scandalous cases in the recent history of Georgia. On February 12, the TV program "P.S." of Rustavi 2 started with information about the special operation carried out at the Tbilisi International Airport. The host of the TV program, Giorgi Gabunia, argued ${ }^{1}$ that the state agencies did not comment on both the arrest of the cleric and the basis on which he was arrested. On the same day, it was reported that the head of the Patriarch's bodyguard, Soso Okhanashvili, who accompanied Ilia II to Germany, was immediately summoned to the Prosecutor's Office for questioning and returned to Berlin a few hours later. In Germany, Ilia II's protection was strengthened by the Special State Protection Service that had not previously protected the Patriarch. Giorgi Mamaladze was arrested while he was traveling to Germany to visit the Patriarch. Ilia II had undergone gallbladder surgery in Germany at that time and was undertaking a course of treatment. Giorgi Mamaladze was sentenced to pre-trial detention as a measure of restraint based on the decision of the Tbilisi City Court. Following dean Giorgi Mamaladze's arrest at Tbilisi International Airport on charges of plotting a murder before leaving for Germany, the investigation did not fully inform the public despite high public interest. The Prosecutor's Office also banned the cleric's

\footnotetext{
${ }^{1}$ G. Bochikashvili, “the Cyanide Case In Brief”, 22.02.2017, Internet source https://on.ge/story/8054\%E1\%83\%AA\%E1\%83\%98\%E1\%83\%90\%E1\%83\%9C\%E1\%83\%98\%E1\%83\%93\%E1\%83\%98\%E1\%83\%A1\%Е1\%83\%A1\%E1\%83\%90\%E1\%83\%A5\%E1\%83\%9B\%E1\%83\%94\%E1\%83\%9B\%E1\%83\%9D\%E1\%83\%99\%E1\%83\%9A\%E1\%83\%94\%E1\%83\%93 [L.s.25.03.2021].
} 
lawyers from publishing their versions of the ongoing proceedings. Only the case witnesses spoke publicly about the details of the affair.

Following the information aired by Rustavi 2, the next day, on February 13, 2017, the Chief Prosecutor of Georgia held a press conference. According to Irakli Shotadze, ${ }^{2}$ a poisonous substance, sodium cyanide in particular, was collected from Mamaladze's luggage, through which, according to the initial version, dean Mamaladze was planning to encroach the life of a high-ranking clergyman.

It is clear from the statement of the Prosecutor's Office that the investigation was launched on February 2, 2017, upon the application of certain citizen. An acquaintance of Dean Giorgi Mamaladze approached the Investigation Agency, claiming the archpriest had asked him to provide him with the poisonous substance of cyanide in a short period of time.

The press conference held by the Prosecutor's Office was followed by numerous public statements by members of the Georgian government, informing the public that His Holiness was safe and a great tragedy was avoided. According to the then-Prime Minister of Georgia, Giorgi Kvirikashvili, ${ }^{3}$ "planned crimes against the country and a reckless attack on the church had been prevented.” The Minister of Justice Tea Tsulukiani noted that Georgia avoided a great tragedy. The statement was also issued by the Administration of the President of Georgia, ${ }^{4}$ stating that "it was planned to encroach the life of a high-ranking clergyman of the Georgian Orthodox Church". The first statement of the Prosecutor's Office, the assessments of the representatives of the authorities and the strengthening of the protection of the Patriarch in Berlin evoked the feeling that the main target of the possible crime was probably Ilia II.

Based on these statements, it is clear that at the initial stage of the investigation, the presumption of innocence of the ruling elite against Dean Mamaladze was violated, as their statements led to the formation of a sharply negative public attitude towards the cleric before the court ruled.

Later in the indictment, the assassination attempt on a high-ranking cleric was replaced by the name of Shorena Tetruashvili, the secretary of His Holiness and Beatitude Ilia II, which contradicts the initial statement that Tetruashvili is not a clergyman, much less a high-ranking one. The release of such contradictory versions by the prosecution may be explained by an attempt to cover up the details of the case, which would have allowed the agency to further maneuver.

Despite the Chief Prosecutor's contradictory statements, Bishop Iakob of Bodbe still focuses on the assassination attempt on His Holiness. ${ }^{5}$ The patriarch's Diocesan Bishop also notes that the need to uphold the presumption of innocence is not necessary before the Lord.

"Thank you, Lord, for overcoming the very grave crime that would have brought the greatest curse upon our nation to kill our Patriarch. I say this because I have seen it from beginning to end. If they repent, absolutely

\footnotetext{
${ }^{2}$ Special briefing regarding the arrest of Archpriest Giorgi Mamaladze by Prosecutor's Office of Georgia, 13.02.2017, https://www.youtube.com/watch?v=4Fs-pSADC2E\&t=2s, [L.s.25.03.2021].

Statement of the Prime Minister, Government of Georgia 13 February 2017 See here: http://gov.ge/index.php?lang_id=\&sec_id=462\&info_id=59800, [L.s.25.03.2021].

${ }^{4}$ The official website of the President of Georgia, Statement of the President of Georgia, 13 February 2017, available here: https:/www.president.gov.ge/geo/pressamsakhuri/siakhleebi/saqartvelos-prezidentis-ganckhadeba.aspx, [L.s. 25.03.2021].

${ }^{5}$ Imedi TV, Kronika, "Reverend Jacob speaks about the version of the assassination attempt on Patriarch", 18 April 2017, 20:20, https://imedinews.ge/ge/politika/10410/meupe-iakobi-patriarqis-mkvlelobis-mtsdelobis-versiaze [L.s.25.03.2021].
} 
everyone will stand by them after repentance and we will share our part of their burden of that gravest crime", said Reverend Iakob in his sermon. ${ }^{6}$

Tbilisi City Court sentenced Mamaladze to 9 years in prison. ${ }^{7} \mathrm{He}$ is accused not of trying to poison the Georgian Patriarch himself, but Shorena Tetruashvili, his secretary and one of the most influential and odious figures of the Patriarchate. This verdict was upheld by the Tbilisi Court of Appeals. As for the Supreme Court, the highest court instance in Georgia, this entity did not accept the mentioned case in the proceedings at all. The cleric finds himself innocent. According to the prisoner, in addition to legal prosecution, he was sentenced to the most severe punishment by his own spiritual brothers: the Dean was denied of communion for two years.

\section{The "Cyanide Case" in the Media}

Were it not for media reports, including audio recordings, almost nothing would have been known about the so-called "Cyanide Case". A part of Soso Okhanashvili's testimony was broadcast by TV Pirveli ${ }^{8}$ on September 8, and on September 26 other fragments of this testimony were also broadcast on TV Pirveli, but in the program "Reaction". ${ }^{10}$ The following became known from Okhanashvili's testimony:

- Shorena Tetruashvili, the secretary of Ilia II, brought a fortune teller to the Patriarchate to find a piece of sorcery and, as Okhanashvili maintains, a doll with needles was found. The Metropolitan of Chkondidi Petre commented on this, saying that Shorena Tetruashvili had recommended the fortune teller to become a nun.

- Shorena Tetruashvili wanted to bring the gallbladder of the Patriarch of the Orthodox Church, Ilia II from Berlin after the operation. Netgazeti contacted the patriarch's doctor, Tsisana Shartava, who said that one of the people in Germany really had such a desire, but could not remember exactly who it was.

- Shorena Tetruashvili asked Soso Okhanashvili for snake venom, which she needed to make medicine. Dean Giorgi Mamaladze says that Shorena Tetruashvili also asked him to find cyanide for her acquaintance goldsmith.

- Shorena Tetruashvili and Giorgi Andriadze, Chairman of the Supervisory Board of the Patriarchate University, arbitrarily housed Turkish citizens accused of terrorism in the house of Ilia II. In response to the accusations of the former head of the Patriarch's security, the chairman of the supervisory board of the Patriarchate University told Rustavi 2 that it was about the Lazs, who have ideological problems with the Turkish authorities and not with the terrorists. However, the Turkish ambassador to Georgia confirmed that one of the persons involved in this case was indeed wanted by the Turkish side on terrorism charges.

- Tetruashvili and Andriadze had also recommended Turkish citizens to obtain Georgian citizenship.

- According to Soso Okhanashvili, the head of the Special State Protection Service, Anzor Chubinidze, during his stay in Berlin, informed him in the morning that Dean Giorgi Mamaladze had been arrested

\footnotetext{
${ }^{6}$ Ibid.

${ }^{7}$ Imedi TV, "The judge has sentenced dean Giorgi Mamaladze to 9 years in prison", 05 September 2017, 12:08, https://imedinews.ge/ge/samartali/26253/mosamartlem-dekanoz-giorgi-mamaladzes-9-tslit-tavisupleb -agkveta-miusaja, [L.s. 25.03.2021].

8 TV Pirveli, Daily News with Etuna Intskirveli, https:/www.myvideo.ge/v/3375333, [L.s.25.03.2021].

${ }_{9}^{9}$ TV Pirveli, Inga Grigolia’s Reaction - announcement 26.09.2017, https://www.myvideo.ge/v/3391253, [L.s.25.03.2021].

10 TV Pirveli, Inga Grigolia's Reaction, https://www.myvideo.ge/v/3392010, [L. s. 25.03.2021].
} 
and cyanide found, when officially, the cyanide extraction time is around 16:00. Netgazeti spoke to Anzor Chubinidze, head of the Special State Protection Service, who confirmed that he had indeed spoken to Soso Okhanashvili on February 10, although, according to Chubinidze, he had not told Okhanashvili that cyanide had been collected from the suitcase. Moreover, according to Chubinidze, at the moment when he was talking to Okhanashvili, he did not have confirmed information about the cleric's arrest at the Berlin clinic.

The full version of one of the main audio-video materials in the "Cyanide Case" was obtained by the "Kurieri" program and presented to the public on September $4 .{ }^{11}$ We learn from the video recording obtained by Rustavi 2 that Mamaladze was asked to come to Berlin by Metropolitan Dimitri.

The "Kurieri" also obtained the full version of the conversation between the golden witness of the prosecution, Irakli Mamaladze and Dean Giorgi, which was recorded a week before the arrest of the cleric. It is known from the mentioned audio-video material that cleric Giorgi Mamaladze wishes to get rid of Shorena Tetruashvili.

The "Kurieri" revealed the following information:

- Dean Giorgi Mamaladze told Irakli Mamaladze that the Metropolitan of Batumi and Lazeti Dimitri Shiolashvili phoned him from Germany and asked to arrive. Dimitri Shiolashvili is the nephew of Ilia II. Moreover, Soso Okhanashvili is his son-in-law. The metropolitan later told Netgazeti that the communication between the dean and him had indeed taken place, but instead, the Dean wrote to him and asked for a blessing on arrival.

- Continuation of the episode of "getting rid" of Shorena Tetruashvili involves Dean Giorgi Mamaladze telling Irakli Mamaladze about the prophecy of Monk Gabriel, according to which Shorena Tetruashvili would be admitted to a psychiatric hospital after the death of the Patriarch and would never be back to the Patriarchate.

- According to the content of the telephone conversation between Dean Giorgi Mamaladze and Tara (Tato) Shavshishvili, a representative of the Patriarchate Security Service, before his arrest, the Archpriest told Shavshishvili that they had to apply to Archil Gamzardia, who had posted on Facebook about the plotting of Partriarch's assassination. Taras Shavshishvili told the "Kurieri" that the Dean had meant applying to the investigative agencies, the Prosecutor's Office, the Ministry of Internal Affairs and the State Security Service.

\section{A different Version of the "Cyanide Case" by Gogashvili}

Ioseb (Soso) Gogashvili, ${ }^{12}$ former Deputy Head of the State Security Service, spoke about his own version of the "Cyanide Case". According to him, former Dean Giorgi Mamaladze, who was serving a sentence for preparing the assassination of Shorena Tetruashvili, the secretary of the Catholicos-Patriarch, should not have been the only one serving his sentence in prison because he had collaborated with the group. Gogashvili also accused Soso Okhanashvili, the former head of the Patriarch's security service, of preparing Tetruashvili's assassination.

\footnotetext{
${ }^{11}$ Rustavi 2, "Kurieri" 21:00, https://rustavi2.ge/ka/news/84130, [L. s. 25.03.2021].

${ }^{12}$ TV Pirveli, scandalous interview of Nodar Meladze with Soso Gogashvili, 13.02.2021, https://www.youtube.com/watch?v=SCvy5_TzRRA, L.s. 25.03.2021].
} 
The former senior State Security Service official ${ }^{13}$ believes that the investigation into the case should be resumed and is ready to play a role in this, including in cooperation with the investigative bodies. Soso Gogashvili says that getting rid of Shorena Tetruashvili had been attempted twice before the scandalous "Cyanide Case". According to him, Tetruashvili's elimination was planned in the fall of 2016 during the Patriarch's visit to Moscow, but the special services found out about it later.

He also talks about the "plan" to use cyanide in the German hospital where the Patriarch was admitted: ${ }^{14}$

"If Mamaladze had crossed the border with cyanide, he would have brought that cyanide and put it on the food that Shorena had to bring to the Patriarch. This would take place at the Helios Clinic in Berlin. At the moment of delivering the poison they would snatch it from her hands. Each corner of the clinic is equipped with cameras and they would also have left the cell phone cameras on as well just to ask her what she was brining. Once she would tell them it was the food, they would suspect something wrong and there would be panic, calling the "Helios" security service. The Berlin police would come, the Foreign Ministry would be informed, and ultimately in Europe, not Russia, the Patriarch's murderer Shorena Tetruashvili would be arrested. She would go to jail as the Patriarch's assassin. They would become heroes, as they would have saved the patriarch, getting rid of Shorena Tetruashvili, the ruler of the reverends, and they would be back to Georgia with their positions solidified. It was initially announced that the liquidation of the Patriarch, a high-ranking hierarch, was planned. This was stated by both the Prosecutor's office and the Prime Minister. When we discussed these materials, I was asked what I thought and I immediately said that the target was Shorena. Giorgi Kvirikashvili rebuked me, saying I held the wrong idea: "you cannot imagine how serious threat they poised to the country and the Patriarch". Apparently, he had more information from the Chief Prosecutor. They wanted to maintain their influence. If Shorena had been poisoned there, an investigation would have been initiated and some kind of version would have developed. The investigation there would find out where the food had come from and put a real investigation would go in that direction. That is, they would still be discredited and identified as criminals". "They did not intend to do that", said Soso Gogashvili, although he could not or did not specify where Giorgi Mamaladze had obtained cyanide.

According to him, Giorgi Mamaladze and the group collaborating with him had targeted not only Shorena Tetruashvili, but also the bishops, the archbishops, who, according to Gogashvili, were problematic for them.

According to the former high-ranking official of the SSS, Mamaladze's group deliberately started disseminating myths about Shorena Tetruashvili, as if she was "standing on a pedestal, giving instructions to the bishops who acted as she had told them".

Regarding the "Cyanide Case", he noted ${ }^{15}$ that the authorities had successfully prevented the crime.

\section{Conclusion}

The internal controversies of the Georgian Church have been publicized: Who is going to replace Ilia II on the Patriarch's throne: Metropolitan Dimitri, Archbishop Iakob or any other high-ranking priest? According to the theologians, a number of unpleasant events inside the Georgian Orthodox Church during the recent period indicates that a furious struggle for the Patriarch's throne is taking place. Is the arrest of the Dean on charges of conspiracy to commit murder a result of this controversy? How or why is the state involved in this process?

\footnotetext{
${ }^{13}$ Ibid.

${ }^{14}$ Ibid.

${ }^{15}$ TV Pirveli, scandalous interview of Nodar Meladze with Soso Gogashvili, 13.02.2021, https://www.youtube.com/watch?v=SCvy5_TzRRA, [ø. C. 25.03.2021].
} 
What role do the Russian special services play in all this? Is this struggle related to the process of selecting the successor of Ilia II to the Patriarchal throne? This is an incomplete list of questions that are of interest to a large part of the Georgian society.

As unimaginable as it may seem, it was the demand for the accused clergyman to be provided with communion, including those known for atheistic sentiments, that stimulated the discrimination against the Church. It should be noted that after the communion of Giorgi Mamaladze, the attack on the church continued with another request to the Patriarch to mediate with the Georgian authorities to pardon Mamaladze as his health was deteriorating rapidly. When it suited them, they could recognize the power of His Holiness's word. They could not easily forget one simple detail: Georgian legislation provides for the initiation of early release proceedings due to deteriorating health, although the authors of this request needed to create the image of a persecuted person from the church through the arrested Dean.

The suspicious and inconsistent actions of Giorgi Mamaladze's associates make it clear that the "Cyanide Case" was invented to discredit the church from the very beginning. What enables us to say this? Despite the fact that Dean Mamaladze was being monitored, the Prosecutor's Office for some reason failed to determine from whom and under what circumstances the clergyman obtained the cyanide on February 2-10; The cyanide was allegedly collected from the luggage compartment of Tbilisi Airport after the Dean checked in and handed over his bag. However, there are no videos proving this evidence either. However, there are several surveillance cameras in the airport area. The dean himself says he was arrested in the car and was unable to get to the airport at all.

If we assume for a moment that such a horrible crime was being committed, obviously we all will agree that neither in terms of preparation nor in terms of execution, one person could not have committed it, especially the dean. We all have a question: who stands behind it all? What was the group this person collaborated with? Instead of the prosecution finding more solid evidence than the other alleged perpetrators, prosecutors say they could not even figure out from whom the dean obtained the cyanide. That is why the fact of collecting this substance from the deacon's luggage raises very big questions in the society.

Sodium cyanide is a toxic substance that absorbs oxygen when it enters the body and causes death; however, as the Georgian experience shows, cyanide may kill not only individuals but also a number of state institutions even without entering anyone's body. Cyanide and the "Cyanide Case" allegedly "broke" the health of the chairman of the Supreme Court of Georgia, who resigned after the court had refused to accept the "Cyanide Case" (The Case of Dean Mamaladze) into proceedings. However, the arrest of Dean Giorgi Mamaladze seemed to have a political undertone from the very beginning and to feel it, no special senses were needed.

Determining one's guilt, which, as a rule, should be within the competence of the court or the, is done through the active participation of government officials. The government is trying to demonstrate force on the church, which serves to discredit it. In fact, the authorities were not motivated by the aim of establishing justice in the case.

One of the main shortcomings of the case is how cyanide was found in Mamaladze's luggage. Mamaladze's luggage was collected at the airport only after he handed over the luggage. The luggage was searched without his presence just nine hours after Mamaladze was arrested. Moreover, this process was not filmed on video cameras. The airport surveillance camera recordings have also been destroyed. 
The verdict was based only on the fact that Mamaladze was searching the Internet for information about cyanide. The verdict fails to substantiate why he was looking for this information and what he needed the cyanide for (According to Mamaladze cyanide is used in icon painting and that is why he was interested in it).

The verdict also maintains that the defense did not present any exculpatory evidence. However, the law does not oblige the defense to present evidence. Rather, it is the prosecution that must obtain evidence to prove that the accused is guilty.

Despite the high public interest, the lawyers were categorically forbidden to speak publicly about the details of the case. The court hearings were also closed without justification. As a result, the public has little information on the subject and the case is still unclear.

The presumption of innocence against Mamaladze was violated as statements against him were made by highranking officials from the moment of his arrest, thus leading to the formation of the public opinion that Mamaladze was guilty. Moreover, at first, without any evidence, it was said that Mamaladze was going to poison the Patriarch.

Representatives of the Prosecutor's Office and the government presented the situation as if the Dean was going to assasinate the Catholicos-Patriarch of Georgia with cyanide. But it soon became clear that cyanide was not intended for the Patriarch, but for a high-ranking clergyman. However, in the end, Dean Mamaladze was sentenced to 9 years in prison not for the murder of any cleric, but for the assassination attempt on Shorena Tetruashvili, the secretary of Patriarch Ilia II. At the same time, he was sentenced to nine years without investigation (court) to determine from whom Giorgi Mamaladze had obtained the cyanide. Moreover, the poisonous substance was collected from his baggage at the airport, when Mamaladze had lost control of the baggage. They were removed so that only police officers were present as witnesses; however, no video recording was attached to the protocol. In addition, the defense was denied access to the airport surveillance camera recordings and fingerprinting. However, neither the Tbilisi City Court nor the Appellate Court corrected the "shortcomings" during the investigation, and the Supreme Court refused to accept the case at all.

On February 10, 2017, the "collected cyanide" at the Tbilisi airport, would be enough to "kill" everyone, since the fight for the patriarchal throne weakens the church, state institutions (confidence to which has fallen sharply) and threatens the national interests of Georgia. 


\section{Bibliography:}

1. G. Bochikashvili, "Cyanide Case in Brief", 22.02.2017, Internet source https://on.ge/story/8054\%E1\%83\%AA\%E1\%83\%98\%E1\%83\%90\%E1\%83\%9C\%E1\%83\%98\%E1\%83\%93\%E1\%83\%98\%E1 \%83\%A1-\%E1\%83\%A1\%E1\%83\%90\%E1\%83\%A5\%E1\%83\%9B\%E1\%83\%94\%E1\%83\%9B\%E1\%83\%9D\%E1\%83\%99\%E1\%83\%9A\%E1\%83\%94\%E1\%83\%93 [Last seen 25.03.2021];

2. Prosecutor's Office of Georgia, special briefing regarding the arrest of Dean Giorgi Mamaladze, 13.02.2017 https://www.youtube.com/watch?v=4Fs-pSADC2E\&t $=2 \mathrm{~s}$, [Last seen 25.03.2021];

3. Statement of the Prime Minister, Government of Georgia 13 February 2017 See here: http://gov.ge/index.php?lang_id=-\&sec_id=462\&info_id=59800, [Last seen 25.03.2021];

4. The official website of the President of Georgia, Statement of the President of Georgia, 13 February 2017, available here: https://www.president.gov.ge/geo/pressamsakhuri/siakhleebi/saqartvelos-prezidentisganckhadeba.aspx, [Last seen 25.03.2021];

5. Imedi TV, Chronicle, "Reverend Jacob speaks about the version of the assassination attempt on Patriarch", 18 April 2017, 20:20, https://imedinews.ge/ge/politika/10410/meupe-iakobi-patriarqis-mkvlelobismtsdelobis-versia -saubrobs, [Last seen 25.03.2021];

6. Imedi TV, "The judge sentenced dean Giorgi Mamaladze to 9 years in prison", 05 September 2017, 12:08, https://imedinews.ge/ge/samartali/26253/mosamartlem-dekanoz-giorgi-mamaladzes-9-tslit -tavisuplebisagkveta-miusaja [Last seen 25.03.2021];

7. TV Pirveli, Daily News with Etuna Intskirveli, https://www.myvideo.ge/v/3375333 [Last seen 25.03.2021];

8. TV Pirveli, Inga Grigolia's “Reaction" - announcement 26.09.2017, https://www.myvideo.ge/v / 3391253 [Last seen 25.03.2021];

9. TV Pirveli, Inga Grigolia's "Reaction”, https://www.myvideo.ge/v/3392010, [Last seen 25.03.2021];

10. Rustavi 2, Courier 21:00, https://rustavi2.ge/ka/news/84130, [Last seen 25.03.2021]. 